\section{An Observational Assessment of a Dementia- specific Horticultural Therapy Program}

\author{
Shannon E. Jarrott, ${ }^{1}$ \\ Hye Ran Kwack, ${ }^{2}$ and \\ Diane Relf ${ }^{3}$
}

Additional indeX words. elderly adults, dementia, adult day service programs, activities

Summary. Horticultural therapy (HT) is used across the lifespan with individuals with a wide range of physical, social, and cognitive abilities. Older adults make up a large group of participants in horticultural activities. As the population of older adults grows, more adults face the risk of experiencing a dementing illness. Many families turn to institutional care programs, such as nursing homes and adult day service (ADS) programs, for assistance with the care of their relative with dementia. HT may be an appropriate activity to incorporate into dementia care activity programs, but formal evaluations of such programs are limited. The current study evaluated a 10 -week HT program conducted with adults with dementia at an ADS program. Observations indicated that participants engaged in the horticultural activities for greater periods of time than the nonhorticultural activities. Participant affect during the horticultural and nonhorticultural activities was comparable. HT is appropriate for dementia care programs serving adults with a wide range of cognitive, physical, and social needs, and it should be considered as a viable alternative to more typical dementia care program activities.

\footnotetext{
Thanks to Christina Gigliotti, Peg Pecora, and Kathy Anderson for their assistance with this project.

${ }^{1}$ Assistant professor, Dept. of Human Development, Virginia Tech, Blacksburg, VA 24061-0416.

${ }^{2}$ Postdoctoral student, Dept. of Horticulture, Virginia Tech, Blacksburg, VA 24061-0327.

${ }^{3}$ Professor, Dept. of Horticulture, Virginia Tech, Blacksburg, VA 24061-0327.
}

$\mathrm{H}$ orticultural therapy is an intervention that uses gardening and cultivating techniques as activities to improve the treatment and rehabilitation of clients with special needs. As action-oriented activities, horticultural and gardening activities have been reported to increase mental and physical rehabilitation, social interaction, sensory stimulation, and self-directed action (Relf and Dorn, $1995)$. Over the last 10 years, a growing number of professionals from institutional care programs for frail elderly, such as ADS programs and nursing homes, have requested information and training in order to incorporate $\mathrm{HT}$ into their activities schedules (personal observation). Mooney and Nicell (1992) reported that HT is especially suitable for older adults because it can be adapted to various levels of physical ability and its benefits can decrease or slow the negative effects of aging (e.g., gait instability) and reduce the occurrence of negative behaviors associated with dementia (e.g., agitation). Additionally, HT may be modified to suit persons with cognitive and social impairments caused by dementia so that individuals can experience success in the activity regardless of their abilities or impairments. For example, an activity may be made more challenging or simpler so that individuals of varying abilities may participate with equal success.

\section{Dementia characteristics}

Individuals with dementing illnesses typically experience progressive impairment in multiple areas of functioning (Cummings and Benson, 1992). New learning is typically affected, as is short term memory, communication, and ability to care for oneself. Progression of cognitive and functional impairments varies depending on the cause of the dementia and the age of onset. For example, individuals with late onset Alzheimer's disease typically experience a continuous and gradual decline in functioning over many years, while a person suffering from vascular dementia due to stroke demonstrates stepwise deterioration with a leveling off of functioning in between periods of decline (Zarit and Zarit, 1998).

\section{Activity, affect, and meaning in dementia care programs}

Because the level of functional, cognitive, and social impairment varies widely among persons with dementia, caregivers at dementia care programs often find it difficult to implement activities that successfully engage carerecipients and provide appropriate levels of stimulation (Felce et al., 1999; Hoffman and Kaplan, 1998; Morgan and Stewart, 1997; Salari and Rich, 2001). As a result, activity levels are often very low at such programs (Morgan and Stewart, 1997). Activities that are presented are often childish, too easy, or too difficult for care-recipients (Salari and Rich, 2001). Such activity programs often serve to increase the older adults' frustrations and may precipitate behavior problems (Alessi et al., 1999; Buettner, 1995; Mooney and Nicell, 1992; Tariot, 1996).

Lawton and Nahemow (1973) argued that an environment that provides stimulation at the same time that it minimizes sources of stress contributes to individuals' competence. Research of program activities supports the value of similarly developed activities that stimulate participants while at the same time reducing stress that might be associated with the activity (Orsulic-Jeras et al., 2000; Sarno and Chambers, 1997). For example, Orsulic-Jeras et al. (2000) described a technique of presenting activities to persons with dementia in which tasks are prepared with "extensions" of the task to accommodate varying levels of participant abilities. A participant who finds the task demanding may be given a downward extension, which is a less difficult form of the task, while someone who completes the task with facility may go on to an upward extension, which adds a dimension of challenge to the activity not present in the initial version of the task. Utilization of this technique with advanceddementia patients in a long-term care facility resulted in increased levels of constructive engagement and high levels of expressed pleasure and interest among participants.

Besides supporting individuals' competencies, activities in dementia care programs should provide meaning to the participants (Kane, 2001). What individuals find meaningful will vary, depending on the personality, physical health, and social history of each individual. Providing person-centered care supports the well-being of individuals and increases the opportunities for individuals to find meaning in their activities and social interactions (Kitwood, 1997). Person-cen- 
tered care requires recognition of personhood (Kitwood, 1997) or an individual's status as a social being with the recognition and respect that entails. However, staff at adult care programs often respond to adults with dementia by focusing on care of the body and neglecting the individual's personhood. Provision of person-centered care requires some knowledge of the individual's social history (Kitwood, 1997). Even among adults with dementia who may not be able to provide social history information themselves, care providers can collect this information and use it to develop an activity program that maintains meaning in the older adults' lives.

Therapeutic horticultural activities provide an ideal opportunity for engaging care-recipients with dementia in appropriate, stimulating, meaningful, and productive activities that can be modified to suit a wide range of cognitive and functional abilities. The activities are appropriate for several reasons: 1) they are familiar to most care-recipients, 2) they are creative and result in a valuable end-product, 3 ) they exercise a wide range of physical and cognitive skills, and 4) they provide many opportunities for meaningful engagement and social interactions, including reminiscence.

\section{Horticultural therapy}

Horticultural and related activities represent the most commonly identified outdoor leisure activity or hobby of older adults (Burgess, 1990; Hill and Relf, 1983; Relf, 1994). For many seniors, horticulture represents a continuity of habits and interests developed earlier in life. According to Atchley (1989), continuity of established structures is an adaptive strategy in the aging process. Although continuity as a means of successful aging is typically applied to nonpathological aging, continuity may be present even in persons experiencing dramatic changes in their circumstances (Lieberman and Tobin, 1983), for example, persons with dementia. For those who typically experience loss of autonomy and abilities, continuity of activities and skills may support a sense of competence and self-esteem by providing predictability at a time when a great deal of negative change occurs.

Individuals engaged in HT activities benefit not only from the physical exercise but the sense of pride and accomplishment associated with horticultural success (Hill and Relf, 1983; Matsuo, 1995). Nurturing plants can provide a sense of responsibility and belonging that is often lacking in institutional dementia care programs. McGuire (1997) states that contact with living plants can stimulate wonder and appreciation within the institutional environment while contributing a new sense of excitement. Therapeutic horticultural activities are often related to anticipation of the future as the gardener waits for the flower and ripening fruit (Lewis, 1988; Relf, 1978).

HT's considerable potential lies largely in its capacity for adaptation to match the needs and abilities of older adults and can serve both to rehabilitate and facilitate new skill development (Sarno and Chambers, 1997). At institutional dementia care programs, a wide range of activities that are developed, implemented, and modified to suit varying participant needs, abilities, and interests has been associated with positive outcomes that promote higher levels of activity, improved mood, and even maintenance of cognitive and functional skills (Bowie and Mountain, 1997; Buettner, 1995; Orsulic-Jeras et al., 2000; Palleschi et al., 1996; Seifert, 1998).

One notable example of the incorporation of horticultural materials into a dementia care program is the Eden Alternative, a philosophy guiding care provision in over 400 longterm care facilities across the country (Thomas, 2002). Created to provide a supportive habitat for residents and care staff, the Eden alternative provides older adult residents with companionship, regular contact with children, plants, and animals, varied and self-directed activities, a voice in decision making, and opportunities to give care to other living things. Although research of the effects of the Eden Alternative have not specifically analyzed the horticultural component of the approach, evaluations of Eden Alternative programs indicated meaningful drops in mortality, medication use, and staff turnover (Bruck, 1997). Horticultural activities are key to the Eden Alternative as they provide residents with the opportunity to pursue familiar activities and provide care for another living being (Thomas, 1996), a benefit achieved in other horticultural programs outside the Eden $\mathrm{Al}$ ternative setting.
Additional potential benefits of HT include sensory stimulation and reminiscence. Sensory stimulation of the tactile, aural, olfactory or visual senses of plants can trigger individuals' memories and stimulate reminiscence (Namazi and Haynes, 1994). Reminiscence activities allow individuals to recall and reflect on previous experiences and the emotions associated with those events. Reminiscence among adults with dementia has been associated with improved well-being (Mills, 1997) and lowered depression (Goldwasser et al., 1987). Research of the effects of sensory stimulation also indicates positive effects on engagement (Lawton et al., 1984), increased interaction (Spaull et al., 1998), selfawareness (Hill and Relf, 1982), productivity, and feelings of depression (Austin, 1991), all of which contribute to greater quality of life (Kane 2001).

\section{Evaluation of horticultural therapy}

To validate $\mathrm{HT}$ objectives and anecdotal reports of beneficial outcomes, HT should be thoughtfully planned building on extant theory and research and documenting the activities' effects on participants. Outcomes may be measured using observational methods, standardized physiological or psychosocial measures (e.g., wellbeing, social participation, behavior problems), and focus groups.

Observation is an advantageous method of data collection as it provides a direct indicator of human activities in a particular environment and maintains high face validity (Vining and Stevens, 1986). Although observational methodologies have been established for many years (Sommer and Sommer, 1980; Zeisel, 1981) and are used in studies of older adults, little HT research has used observational methods of evaluation. Examples of observational HT research include the work of Sarno and Chambers (1997), who observed change in verbal behavior and social interaction among aphasia patients as a result of a HT program, and Kerrigan and Stevensen (1997) and Predny and Relf (2000), who observed interactions between children and older people during HT activities.

Because horticultural activities are developmentally and socially appropriate for adults with dementia, pro- 
gram staff might find that a HT program results in increased activity level and improved mood among those participants joining the $\mathrm{HT}$ activities compared to participants' response to more typical program activities. The current paper presents a HT program developed for persons with dementia in an ADS center and discusses the findings of an observational assessment of the activities.

\section{Methods}

Therapeutic horticultural activities were developed for an ADS program primarily serving persons with dementing illnesses. The goal of the HT program was to develop and implement stimulating, appropriate activities, planning for modifications that might be required for inclusion of all interested care-recipients. Second, because evaluation research of HT programs for persons with dementia is limited, the authors focused on describing whether the HT activities effectively engaged the participants and how the HT activities affected participants' moods. Finally, effects of the HT activities were compared to the effects of more typical ADS activities.

The authors generated three hypotheses related to theory and research of dementia care programs and therapeutic horticultural activities: 1) time spent doing nothing will be lower during HT activities than during nonhorticultural (non-HT) activities; 2 ) time spent engaged in the presented horticultural activity during the HT sessions will be greater than time spent constructively engaged during nonHT activities; and 3) affect, or mood, will be more positive during HT than non-HT activities. Additionally, the authors expected that regular, frequent exposure to HT activities would result in increased time participants spent engaged in the horticultural activities. Finally, it was expected that affect expressed by participants during the horticultural activities would become more positive over the course of the study.

\section{Subjects}

Participants attend a universitybased ADS program, which primarily serves older adults with dementing illnesses. The program provides care for up to 18 adults each day.

Caregivers of 11 participants with dementia completed informed consent forms for participation in the HT activities. However, because two of these individuals missed most of the horticultural activities, we conducted analyses only on the nine participants who regularly engaged in HT activities. Six caregivers never completed consent forms, despite repeated efforts to secure their consent. No caregiver indicated an intentional refusal to consent. Data was not collected on the family members of these caregivers. All of the participants were white, with an average age of 79 years. Each participant had received a diagnosis of a dementing illness. The average level of impairment was moderate as assessed by the Mini-Mental Status Exam (MMSE) (Folstein et al., 1975), but scores ranged from severe impairment $(\mathrm{MMSE}=8)$ to normal cognitive functioning (MMSE = 27).

\section{Procedures}

Two HT students with experience working with older adults and persons with cognitive impairments developed and implemented a schedule of HT activities for the participants. Activities were selected for anticipated therapeutic value and simplicity of presentation and potential modification for participants' wide range of abilities. Additionally, all of the plant material to be used in the proposed activities was checked to ensure that only nontoxic materials were used. This added precaution was taken because some dementia patients will place nonfood items in their mouths.

HT activities were presented three times each week over a 10 -week period. Activities lasted 30 to $45 \mathrm{~min}$ per session. Because the activities were presented during the summer, most activities were done outside and involved planting and tending seedlings / plants (e.g., shade plants, herbs, fruits, and vegetables). Some plants were started from seeds, but primarily rooted plants with top growth were used throughout the course of the project. Other horticultural activities included cooking with herbs, craft activities (e.g., pressed flower vases), and sensory stimulation activities (e.g., smelling and touching herbs). Data from these other horticultural activities are not analyzed in the current paper. Modifications to the horticultural activities were planned to suit individual abilities and needs. For example, during the planting activity, if a participant was unable to stand at the raised beds and plant the seedlings, the participant remained seated at a central table and was asked to mix soil and fertilizer for the beds. Activities common to ADS programs were presented by the program's activity director before and after the HT sessions. Examples of these activities include crafts, cooking, current events discussions, snacks, and lunch.

\section{Measures}

An observational assessment was developed for the present study. Coding schemes used in other HT observational studies were considered but were not appropriate for the dementia group at this program or the focus of the activities. Because the current study is largely exploratory, the authors sought to describe the activity and mood exhibited by participants during the HT and non-HT activities using a simple coding scheme.

The observers coded participants for activity and affect. Such a coding scheme is valuable as other observation schemes often address behavior only, or they implicitly tie affect to behavior (e.g., horticultural behavior with positive affect), which may be inappropriate. The behavior codes were developed by the first author to represent broad categories of activities typically seen at dementia care programs and to allow identification of engagement in therapeutic horticultural activities. The affect scale was adapted from the Dementia Care Mapping scale (Bradford Dementia Group, 1997) to be used in conjunction with the behavior codes.

Two research assistants were trained to collect observational data. Observer training involved extensive discussion of codes and two days of practice observations. Following the training session, observational data were collected to test for inter-rater agreement, and a reliability rate of $85 \%$ (Fleiss, 1981) was achieved. Data from this inter-rater reliability check were not used in analyses.

The practice observations made during the reliability check were valuable not only because they refined observers' coding skills but because the sessions familiarized observers with expression of affect associated with earlier versus later stages of dementia. In later stages of dementia, affect is typically flat in comparison to persons with mild dementia (Zarit and Zarit, 
1998). Consequently, expressed mood that may indicate mild positive affect in a less impaired individual may indicate high positive affect in a more severely impaired participant.

Observers each coded activity and affect for six participants over a 90 -min period. Observations began $30 \mathrm{~min}$ before the HT activity, continued through the activity, and concluded about $30 \mathrm{~min}$ after the HT activity ended. The observation scale developed for the current study is based upon the Dementia Care Mapping technique (Bradford Dementia Group, 1997). As with the Dementia Care Mapping technique, observers in the current study recorded two codes for each participant every 5 min during the observation period: 1) a letter code indicating the predominant behavior for the 5-min period and 2) a numeric code indicating the predominant level of affect expressed during the time frame. Observers used digital timers with a second counter to accurately determine the most predominant behavior and affect in situations where these indicators fluctuated during the 5-min period. Practice observations revealed that ADS participants' type of behavior and expressed affect typically did not change very much within any 5 -min period, making it manageable for observers to identify the predominant behavior and mood for a given time frame. The codes for the current observational scale are different from those used with the Dementia Care Mapping technique; fewer codes are used in order to simplify the observation scheme and focus on salient behaviors. The codes are presented in Table 1 with a brief description of each code.

One exception to the rule of coding the predominant behavior in a time frame was when a participant spent the majority of the time frame doing nothing but engaged briefly in some other activity during the time frame. For example, if a participant spent 4 min staring at the table but 1 min engaged in conversation with a staff member, the letter code assigned to this time frame would be $S$ for social behavior rather than $\mathrm{N}$ for nonproductive, nonsocial behavior. This exception was created to capture behaviors, however brief, that illustrated active involvement in the program surroundings and activities and indicated potential for engagement in program activities.

Observations were made directly while the activity was conducted. Observers tried to remain in the background, but participants would occasionally initiate an interaction with observers. Time frames in which a participant interacted with an observer were not included in calculations used in data analysis because of the potential effect on observational codes. Observational data were collected for each session of horticultural activities.

\section{Data analysis}

Data processing of observational data included calculation of the average level of affect during the HT and nonHT activities (pre-HT and post-HT observations were combined) for each participant. Additionally, the percentage of time spent engaged in the different behaviors during $\mathrm{HT}$ and non-HT activities was calculated. In order to test the proposed hypotheses, a series of $\mathrm{t}$ tests was conducted. Due to the extreme variability in attendance at the ADS program (due to transportation problems, family vacations, and participant illness), data was collected on each day of the horticultural program to maximize the usable data available. One day's observations collected during the first, fourth, and eighth weeks of the study were selected for comparison, which allows for consideration of a nonlinear relationship between $\mathrm{HT}$ and the dependent variables over time. These dates were selected for comparison because they were attended by the most participants, (nine participants each day), and the content of the sessions was similar [planting seedlings or 2 to 4inch $(5$ to $10-\mathrm{cm})$ potted plants was done on each of these days]. Non-HT activities on these days varied.

Paired sample $t$ tests were conducted to determine differences in level of activity and affect during the $\mathrm{HT}$ and non-HT activities in week 1 (Wl), week 4 (W4), and week 8 (W8) of the HT

Table 1. Summary of the behavior and affect codes recorded for each participant every 5 min to indicate the predominant behavior and affect exhibited during observations made of the horticultural therapy and nonhorticultural activities conducted with older adults with dementia at the adult day service program.

\section{Code Description of behavior codes}

P Productive, nonhorticultural: Engaged in a productive, nonrepetitive behavior other than horticultural activities (e.g., reading, eating, playing a game, engaging in a craft activity, singing)

$\mathrm{H} \quad$ Horticultural: Engaged in the presented or an alternate horticultural activity. " $\mathrm{H}$ " may be coded any time during the observation period as some participants engage in horticultural behavior spontaneously, regardless of the activity being presented.

S Social, nonproductive: Interacting with others verbally or otherwise without engaging in otherwise productive or horticultural behavior.

N Nonproductive, nonsocial: appearing passive, withdrawn, or exhibiting repetitive/self-stimulating behavior (e.g., sleeping, staring into the distance, pacing, observing nearby activity).

Affect Codes

+5 Highly positive affect: Sustained activity or interaction that is clearly therapeutic. Participant exhibits high interest and clear signs of joy.

+3 Moderate positive affect: Sustained activity or interaction with clear interest and enjoyment in activity. Activity or interaction is beneficial to participant.

$+1 \quad$ Mild positive affect: Intermittent activity or interaction with mild interest in activity. No apparent signs of ill-being.

-1 Mild negative affect: Slight ill-being visible. May include boredom or restlessness.

-3 Moderate negative affect: Considerable ill-being. Participant may display sustained anger, moving deeper into apathy and withdrawal.

-5 Extreme negative affect: Extreme apathy, withdrawal, rage, grief, or despair. 
Table 2. The average percentage of time engaged in coded behaviors by participants with dementia during horticultural therapy (HT) and nonhorticultural (non-HT) activities at weeks 1,4 , and 8 of a 10 -week horticultural therapy program.

\begin{tabular}{|c|c|c|c|c|c|c|}
\hline \multirow{3}{*}{$\begin{array}{l}\text { Behavior } \\
\text { code }\end{array}$} & \multicolumn{6}{|c|}{$\begin{array}{l}\text { Observations (\%) of HT and non-HT } \\
\text { activities predominated by specific behaviors }\end{array}$} \\
\hline & \multicolumn{2}{|c|}{ Week 1} & \multicolumn{2}{|c|}{ Week 4} & \multicolumn{2}{|c|}{ Week 8} \\
\hline & HT & non-HT & HT & non-HT & HT & non-HT \\
\hline Nonproductive & 25.6 & 43.3 & 26.8 & 58.9 & 17.0 & 37.1 \\
\hline$(\mathrm{SD})$ & $(26.5)$ & $(28.3)$ & (23.9) & $(26.2)$ & $(21.1)$ & $(27.5)$ \\
\hline Horticultural & $64.4^{y}$ & 2.2 & $57.6^{x}$ & 6.3 & $81.3^{\mathrm{w}}$ & 4.1 \\
\hline$(\mathrm{SD})$ & $(33.2)$ & $(6.7)$ & $(39.7)$ & (14.5) & $(21.0)$ & $(12.3)$ \\
\hline \multicolumn{7}{|l|}{ Productive/ } \\
\hline non-HT & 1.1 & 20.0 & 1.1 & 25.6 & 0.0 & 59.2 \\
\hline (SD) & $(3.3)$ & $(30.0)$ & $(3.3)$ & (20.9) & $(0.0)$ & $(23.9)$ \\
\hline Social & 8.9 & 34.4 & 14.6 & 9.3 & 1.0 & 0.0 \\
\hline (SD) & $(9.3)$ & (19.4) & $(18.1)$ & (18.8) & $(3.0)$ & $(0.0)$ \\
\hline
\end{tabular}

${ }^{\mathrm{z} P}<0.05$ for time spent doing nothing during HT compared to non-HT activities at Week 4. $P=0.08$ for time spent doing nothing during HT compared to non-HT activities at Week 8 .

${ }_{\mathrm{y}, \mathrm{x}, \mathrm{w}} P<0.05$ for time engaged in horticultural behavior during HT compared to productive behavior during nonHT activities at Week 1,4 , and 8 respectively.

activities. Additionally, $t$ tests were conducted to determine if there was a significant change in activity or affect in horticultural activities from W1 to W4, from W4 to W8, and from W1 to W8.

\section{Results}

Analyses are presented in two sections: 1) analysis of behavior codes and 2) analysis of levels of affect during horticultural and non-HT activities. Table 2 presents the average percentage of time engaged in specific behaviors. Findings support the first hypothesis that the proportion of time spent doing nothing would be lower during the horticultural activities than during the non-HT activities. The proportion of time spent doing nothing during the horticultural activities was lower than during non-HT activities at each point of comparison, however, this difference was significant only at W4 $(P<0.05)$ and approached significance at W8 $(P=$ $0.08)$. Consequently, the first hypothesis is partially supported.

Looking at the portion of time participants engaged in productive behavior (horticultural or non-HT), the authors found support for the second hypothesis that the portion of time engaged in the presented activity would be higher during the HT activities than during the non-HT activities. At each point of analysis participants spent a significantly greater proportion of their time $(P<0.05)$ during the HT activity engaged in horticultural behavior than was spent in productive behavior during non-HT activities. Related to this hypothesis, the authors considered whether the proportion of time spent engaged in horticultural behavior during the horticultural activities changed over the course of the study. Although the percentage of time in horticultural behavior during HT activities did not change significantly from Wl to W4, there was a significant increase from $\mathrm{W} 4$ to $\mathrm{W} 8(P$ $<0.05)$ and between $\mathrm{Wl}$ and W8 $(P<$ $0.05)$. Figure 1 presents a graph of the level of engagement in the HT activities during Weeks 1, 4, and 8.

Hypothesis three proposed that affect during the HT activities would be higher than during the non-HT activities. Participants exhibited moderate affect, or well-being, at all points of measurement in both HT and non-HT activities with no significant differences between the two types of activities $(P>$ $0.10)$. The average level of affect expressed by the participants ranged from 1.5 to 2.5 for the non-HT activities (maximum $=5.0)$ and from 1.7 to 2.4 for the HT activities, indicating mild to moderate levels of well-being. Consequently, the third hypothesis is not supported. The authors also analyzed change in affect during HT activities over the course of the study, and no significant change was detected $(P>$ $0.25)$.

\section{Discussion}

The present study offers additional means of evaluating HT programs and supports the viability of HT activities in dementia care programs. The means of data collection used in the present study are extensive in comparison to other methods of HT assessment with dementia specific programs. Consequently, the authors were able to analyze not only how individuals responded behaviorally to the presented activities but also how they responded effectively.

Affect was not higher during the HT than the non-HT activities, but the affect participants exhibited indicated moderate well-being, and there were no instances of ill-being exhibited during either the HT or non-HT activities. Participants responded with positive affect to HT from the start, and the positive emotional response continued throughout the course of the

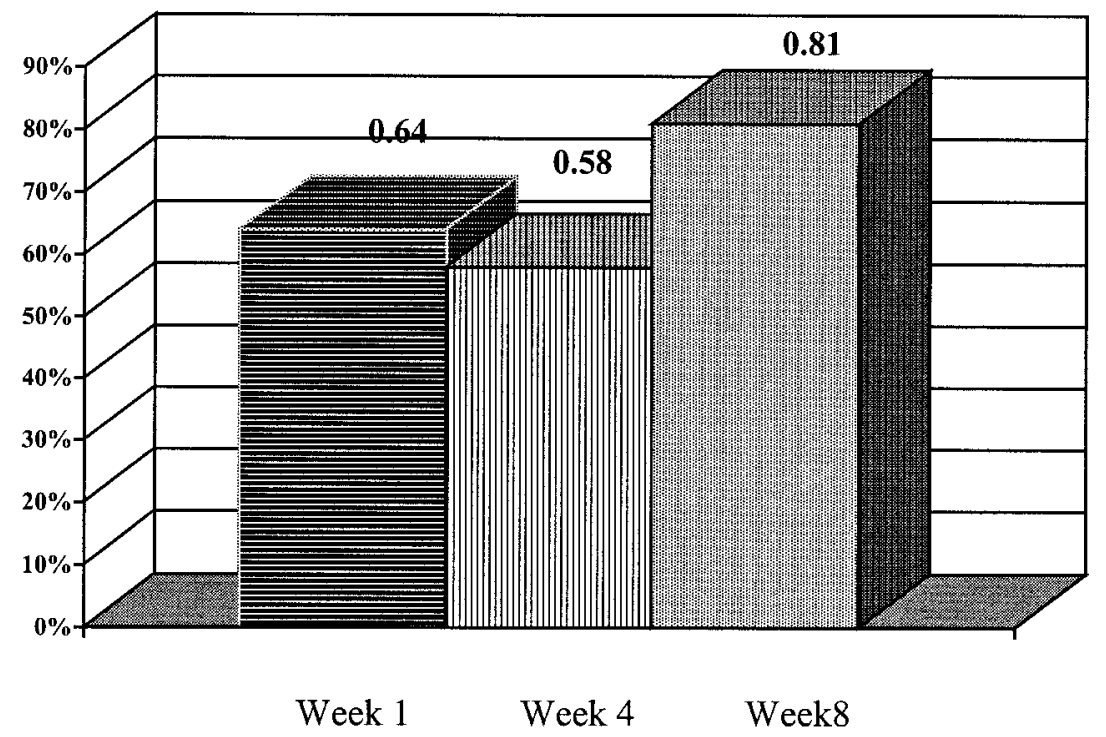

Fig. 1. Percentage of time engaged in horticultural behavior by adult day service participants with dementia during the presented horticultural therapy (HT) activities at Weeks 1,4 , and $8 ; P<0.05$ for time engaged in horticultural behavior during HT activities at Week 1 compared to Week 8 and between Week 4 compared to Week 8 . 
study. While the lack of higher affect ratings during HT compared to nonHT activities does not support HT as a more desirable program activity, such findings indicate that $\mathrm{HT}$ can play a role in maintaining moderate levels of affect among persons with dementia.

The amount of time spent engaged in the presented activity was significantly higher during HT than non-HT activities, and the amount of time spent doing nothing showed a trend of being lower during HT than non-HT activities. Such findings are encouraging, suggesting that $\mathrm{HT}$ activities are a viable alternative to more standard ADS activities. The findings are also important because the group of participants varied widely in cognitive and physical abilities. Some dementia care programs will report an inability to perform certain activities with all participants because of the high care needs of participants, while others try to cater to the lowest functioning individuals in a program (Salari and Rich, 2001) and lose the interest of higher functioning adults in the process. In the program studied, participants with a wide range of cognitive, physical, and social needs were able to willingly and successfully engage in the HT activities. Although some participants could easily complete an activity presented by the horticultural therapist, some participants required constant supervision and direction to remain engaged in the behavior. The nature of the HT activities, along with skilled facilitation, enhanced the participants' opportunities for success and reduced their chance of failure with activities that could be modified to suit the adults' abilities.

Only a few participants did not participate in the activities. One gentleman paced continuously and would not stop to participate in any activities, and some participants periodically refused to perform the activity but would join the group and socialize with other participants during the session. Conversely, there were participants who rarely engaged in other ADS activities but who relished the HT activities. Additionally, some participants who rarely initiate behaviors or who cannot perform relatively simple tasks were able to initiate horticultural behaviors or could identify by sight, touch, and smell a wide range of plants. A particular strength of HT activities is that they are familiar to many older persons. Although cognitive functioning in dementia typically impairs new learning and short-term memory, long-term memory often remains intact very late into the disease. Thus HT provided participants with a valuable opportunity for reminiscence and competence that would not be possible in new activities or situations.

As anticipated, the percentage of time spent engaged in horticultural behavior during the presented HT activities increased over the course of the study. Interestingly, the increase was not evident by week four of the study but was apparent by the study's end. This may reflect participants' need either to become familiar with the person leading the HT activities or to reacquaint themselves with horticultural activities. If the program's activity director had presented the HT activities to the present group of participants instead of a horticultural therapist new to the program, the authors might have detected a more immediate response to the activities. At the same time, the authors feel that part of the success of the HT program was use of HT students familiar with the activities and the population.

Another possible explanation for the increased engagement in the HT activities over the course of the project is that the planting activities became more appealing as the gardening area grew more beautiful and lush with the fruits of the participants' labor. Participants worked with plants with top growth from the start of the project, as opposed to starting everything from seed, so the authors do not believe that participants were dissuaded from early participation because of a lack of living material with which to work. However, the activities conducted early in the project may have been considered more work-like as efforts went into cleaning up the garden area, weeding, mixing soil, and transplanting plants into the raised beds and containers. Work done towards the end of the project often involved harvesting fruit and transplanting flowers and plants to pots for participants to take home as the garden overgrewits physical confines. Such a change, even in similar activities (planting), may have made participation more appealing to the adults as they enjoyed the beauty of the garden and anticipated bringing some of the garden home.

Key to the finding that engagement in HT activities increased over the course of the study is the indication that program and activity directors at de- mentia care programs must permit a reasonable trial period for horticultural activities before assessing the benefits of HT. Care staff should recognize that participants' response to and the benefits accrued from HT may not start out at a peak level, but rather take a period of time to develop. Just as relationships and gardens take time to mature, so do individuals require time to become accustomed with an activity as they decide whether or not it appeals to them as a stimulating and meaningful activity.

Several steps could be taken to improve upon the methods utilized in the current project. First, a larger sample could be studied to provide a greater representation of the population of older adults with dementia. The group of participants in the present study represented a wide range of functional abilities and impairments, yet the full gamut of cognitive and social impairment commonly associated with dementia was not represented. A larger sample would increase the statistical power of the data analyses and thus the generalizability of the findings to other dementia care settings.

Second, the current analyses are based on $3 \mathrm{~d}$ of observations, during which similar planting activities were performed. Controlling for the content of the HT activity was important for comparison to non-HT activities, but future research should compare the effectiveness of different types of HT activities. It may be that individual participants' responses to activities vary depending on their familiarity with an activity, or researchers may find that some types of HT activities (for example cooking, crafts, or planting) are consistently more effective than others.

Although the observational technique utilized possesses advantages over many earlier methods of evaluating HT programs, it does not permit a comprehensive analysis of the participants' experiences. Interviews conducted with the participants could yield valuable insight to the adults' experiences with HT: what they enjoyed or disliked about the activities, how they felt working with the horticultural therapist and with their peers, what they found challenging about the activities, and specifically what kinds of activities they would like to do more or less often. Although gerontologist and care providers previously argued, and some still contend, that adults with dementia cannot provide reliable information, recent research 
indicates that even adults who are moderately cognitively impaired can state consistent choices regarding their care preferences and choices (Feinberg and Whitlatch, 2001).

Future research of HT should expand to include a larger sample and a multi-method approach to evaluating the effects of HT activities on the adult participants with dementia. Differential effects of type of HT activities should be considered as well as the differential experiences of participants. By utilizing a combination of methods, researchers will have a stronger base upon which to construct a comprehensive model of HT programs for older adults with dementia.

\section{Conclusion}

Institutional care programs for persons with dementia face considerable challenges every day as they attempt to provide stimulating, age and ability appropriate activities for their older adult participants. Many programs fall short of providing such a range of activities. As a result participants may be frustrated with activities that are too challenging, they may be bored with activities that are too simple, or they may be irritated with the lack of choice in activities. The present study illustrates the potential value in implementing therapeutic horticultural activities for this population. Horticultural activities provide older adults with opportunities for continuity of old skills and hobbies, reminiscence of earlier years, physical activity, and sensory stimulation. When planned carefully, HT activities can be modified to suit a wide range of physical, cognitive, and social needs of adults with dementia. As such, HT represents a viable and valuable alternative to more traditional activities offered at dementia care programs. Researchers in HT and dementia care programs need to continue assessing the effects of $\mathrm{HT}$ on persons with dementia so that a more complete understanding of the process and effects of such activities may be established.

\section{Literature cited}

Alessi, C.A., E.J. Yoon, J.F. Schnelle, N.R. Al-Samarrai, and P.A. Cruise. 1999. A randomized trial of a combined physical activity and environmental intervention in nursing home residents: Do sleep and agitation improve? J. Amer. Geriatrics Soc. 47:784791.

Atchley, R.C. 1989. A continuity theory of normal aging. Gerontologist 29:183-190.

Austin, D.R. 1991. Therapeutic recreation, processes and techniques. $2^{\text {nd }}$ ed. Sagamore, Champaign, Ill.

Bowie, P. and G. Mountain. 1997. The relationship between patient behaviour and environmental quality for the dementing. Intl. J. Geriatric Psych. 12:718-723.

Bradford Dementia Group. 1997. Evaluating dementia care: The DCM method. $7^{\text {th }}$ ed. Bradford Dementia Group, Bradford, U.K.

Bruck, L. 1997. Welcome to Eden. Nursing Homes (January):28-32.

Buettner, L. 1995. Therapeutic recreation as an intervention for agitation in person's with dementia: A case study of Mrs. M. Therapeutic Recreation J. 29:63-69.

Burgess, C.W. 1990. Horticulture and its application to the institutionalized elderly. Activities Adaptation and Aging 14(3):5161.

Cummings, J.L. and D.F. Benson. 1992. Dementia: A clinical approach. $2^{\text {nd }}$ ed. Butterworth-Heinemann, Stoneham, Mass.

Felce, D., K. Lowe, J. Perry, E. Jones, H. Baxter, and C. Bowley. 1999. The quality of residential and day services for adults with intellectual disabilities in eight local authorities in England: Objective data gained in support of a social services inspectorate inspection. J. Appl. Res. Intellectual Disability 12:273-293.

Feinberg, L.F. and C. J. Whitlatch. 2001. Are persons with cognitive impairment able to state consistent choices? The Gerontologist 41:374-382.

Fleiss, J.L. 1981. Statistical methods for rates and proportions. Wiley, New York.

Folstein, M.F., S.E. Folstein, and P.R. McHugh. 1975. "Mini-Mental State": A practical method for grading the cognitive state of patients for the clinician. J. Psych. Res. 12:189-198.

Goldwasser, A.N., S.M. Auerbach, and S.W Harkins. 1987. Cognitive, affective, and behavioral effects of reminiscence group therapy on demented elderly. International J. Aging Human Dev. 25:209-222.

Hill, C.O. and P.D. Relf. 1983. Gardening as an outdoor activity in geriatric institutions. Activities Adaptation and Aging 3:4754.

Hoffman, S.B. and M. Kaplan. 1998. Problems encountered in the implementation of dementia care programs. Amer. J. Alzheimer's Dis. 13:197-202.

Kane, R. 2001. Long-term care and a good quality of life: Bringing them closer together. The Gerontologist 41:293-304.
Kitwood, T. 1997. Dementia reconsidered: The person comes first. Open Univ. Press, Philadelphia.

Kerrigan, J. and N.C. Stevenson. 1997. Behavioral study of youth and elders in an intergenerational horticultural program. Activities Adaptation, and Aging 22:141153.

Lawton, M.P., M. Fulcomer, and M. Kleban. 1984. Architecture for the mentally impaired elderly. Environ. Behavior 16:730757.

Lawton, M. P. and L. Nahemow. 1973. Ecology and the aging process, p. 619-674. In: C. Eisdorfer and M.P. Lawton (eds.). Psychology of adult development and aging. Amer. Psychol. Assn., Wash., DC.

Lewis, C.A. 1988. Hidden value: A look at the often overlooked profits plants generate for our peace of mind. Amer. Nurseryman (Aug 15):111-122.

Lieberman, M.A. and S.S. Tobin. 1983. The experience of old age, coping, and survival. Basic Books, New York.

Matsuo, E. 1995. Horticulture helps us to live as human beings: Providing balance and harmony in our behavior and thought and life worth living. Acta Hort. 391:19-30.

McGuire, D.L. 1997. Implementing horticultural therapy into a geriatric long-term care facility, p. 61-80. In: S.E. Wells (ed.). Horticultural therapy and the older adult population. Haworth Press, Binghamton, N.Y.

Mills, M.A. 1997. Narrative identity and dementia: A study of emotion and narrative in older people with dementia. Aging Soc. 17:673-698.

Mooney, P. and P.L. Nicell. 1992. The importance of exterior environment for Alzheimer residents: Effective care and risk management. Healthcare Mgt. Forum (Summer):23-29.

Morgan, D.G. and N.J. Stewart. 1997. The importance of the social environment in dementia care. Western J. Nursing Res. 19:740-761.

Namazi, K.H. and S.R. Haynes. 1994. Sensory stimuli reminiscence for patients with Alzheimer's disease: Relevance and implications. Clinical Gerontologist 14(4):29-45.

Orsulic- Jeras, S., K.S. Judge, and C.J. Camp. 2000. Montessori-based activities for long-term care residents with advanced dementia: Effects on engagement and affect. The Gerontologist 40:107-111.

Palleschi, L., F. Vetta, E. Degennaaro, G. Idone, G. Sottosanti, W. Gianni, and V. Marigliano. 1996. Effect of aerobic training on the cognitive performance of elderly patients with senile dementia of Alzheimer's 
type. Arch. Gerontol. Geriatrics (Supplement 5):47-50.

Predny, M.L. and D. Relf. 2000. Interactions between elderly adults and preschool children in a horticultural therapy research program. HortTechnology 10:64-70.

Relf, P.D. 1978. Horticulture as a recreational activity. Amer. Health Care Assn. J. 4(5):68-71.

Relf, P.D. 1994. Gardening in raised beds and containers for older gardeners and individuals with physical disabilities. Va. Coop. Ext. Publ. 426-020.

Relf, D. and S. Dorn. 1995. Horticulture: Meeting the needs of special populations. HortTechnology 5:94-103.

Salari, S.M. and M. Rich. 2001. Social and environmental infantilization of aged persons: Observations in two adult day care centers. Intl. J. Aging Human Dev. 52:115134.

Sarno, M.T. and N. Chambers. 1997. A Horticulture Therapy program for individuals with acquired aphasia. Activities Adaptation and Aging 22:81-91.

Seifert, L.S. 1998. Structured activities reveal residual function in Alzheimer's type dementia. Clin. Gerontologist 19:35-43.

Sommer, R. and B. Sommer. 1980. A practical guide to behavioral research. Oxford Univ. Press, New York.

Spaull, D., C. Leach, and I. Frampton. 1998. An evaluation of the effects of sensory stimulation with people who have dementia. Behavioral Cognitive Psychotherapy 26:77-86.

Tariot, P.N. 1996. Treatment strategies for agitation and psychosis in dementia. J. Clin. Psychol. 57:21-29.

Thomas, W. 1996. Life worth living: How someone you love can still enjoy life in a nursing home: The Eden alternative in action. VanderWyk \& Burnham, Acton, Mass.

Thomas, W. 2002. Honoring excellence in our Edenized facilities. Eden Alternative. 22 Mar. 2002. <http:// www.edenalt.com/home/index.htm>.

Vining, J. and J.J. Stevens. 1986. The assessment of landscape quality: Major methodological considerations, p. 167186. In: R.C. Smardon, J.R. Palmer, and J.P. Felleman (eds.). Foundations for visual project analysis. Wiley, New York.

Zarit, S.H. and J.M. Zarit. 1998. Mental disorders in older adults: Fundamentals of assessment and treatment. Guilford Press, New York.

Zeisel, J. 1981. Inquiry by design: Tools for environment-behavior research. Brooks Cole, Monterey, Calif.

\section{In-row Spacing and Cultivar Affects Ear Yield and Quality of Early-planted Sweet Corn}

\author{
Anusuya Rangarajan, ${ }^{1}$ \\ Betsy Ingall, ${ }^{2}$ \\ Michael Orfanedes, ${ }^{3}$ and \\ David Wolfe ${ }^{4}$
}

Additional IndeX words. plant population, ear length, Zea mays, varieties, stand establishment

Summary. Early-planted fresh market sweet corn (Zea mays) is prone to nonuniform ear length and quality due to uneven germination in cool soils. Growers compensate by reducing in-row spacing at seeding, to increase final plant stand. This risk management strategy was suspected to be reducing quality of early-planted sweet corn, based upon buyer feedback. Four experiments were conducted in upstate New York, to examine the effects of in-row spacing and cultivar on early-planted sweet corn ear yield, length and uniformity. Cultivars examined included 'Temptation' (4 years), 'Sweet Symphony' (3 years) and 'Seneca Spring' ( 2 years). In-row spacings tested ranged from 6 to 9 inches $(15.2$ to $22.9 \mathrm{~cm})$, using a 30 -inch $(76.2-\mathrm{cm})$ between-row spacing. In-row spacing and cultivar influenced marketable yield, husked ear weight and length of early-planted corn, but the extent varied by year. Despite improvements in individual ear weight and length at wider in-row spacing, marketable yield was usually

\footnotetext{
This research supported in part by grants from the Pennsylvania Vegetable Research and Development Fund, New York Fresh Market Vegetable Research Fund, the Eden Valley Growers Cooperative (NY) and USDA Hatch Project 145406

${ }^{1}$ Assistant professor, Department of Horticulture, Cornell University, Ithaca NY 14853.

${ }^{2}$ Research technician, Department of Horticulture, Cornell University, Ithaca NY 14853.

${ }^{3}$ Extension educator. current address: University of Florida Cooperative Extension, Ft. Lauderdale.

${ }^{4}$ Associate professor, Department of Horticulture,
} Cornell University, Ithaca NY 14853. higher at more narrow spacings. Increases in ear weight at wider spacings were usually associated with increases in weight of the outer, green husk. Average ear length of a cultivar varied between 0.2 and 0.6 inches $(0.5$ to $1.5 \mathrm{~cm})$ in response to spacing. If ears longer than 7 inches $(17.8 \mathrm{~cm})$ were desired, $40 \%$ to $60 \%$ of ears satisfied this criteria if harvested from plants grown at 8 -inch $(20.3-\mathrm{cm})$ in-row spacing or a plant population of 26,000 plants/acre $(64,200$ plants/ha). Ear weight and length of 'Seneca Spring' was not as affected by the in-row spacing treatments compared to the other two cultivars, perhaps due to the small size of this cultivar. Selection of smaller sized sweet corn cultivars for planting at high plant populations (6-inch inrow spacing) may reduce the variation in ear weight under challenging early season conditions. For cultivars with similar growth characteristics and maturities of 'Temptation' and 'Sweet Symphony,' a minimum in-row spacing of 8 to 9 inches or a plant population of 23,200 to 26,000 plants/acre $(57,300$ to 64,200 plants/ha) was recommended to minimize variation in ear yield and quality from first bareground plantings in the northeastern United States.

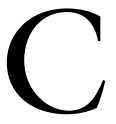
ool soil temperatures and climatic conditions during first early, bareground plantings of sweet corn can cause poor germination and reduced stands. Some growers may compensate by increasing seeding rates for early plantings. However, at high population densities, ear quality can be negatively affected by reduced light interception and increased competition for soil resources (Wolfe et al., 1997). This earlyplanted corn targets a high-value market. Some buyers in the northeastern United States, however, have complained about nonuniform ear appearance and length of locally grown, early sweet corn (personal communication). In an informal survey of current practices, growers reported using in-row spacings from 6 to 10 inches ( 15.2 to $25.4 \mathrm{~cm})(30$-inch between-row spacing) for their first bareground planting of sweet corn. This represented a range of plant populations from 20,900 to 34,800 plants /acre $(51,600$ to 86,000 plants/ha).

Most published research on sweet corn spacing and plant populations 